Proceedings of the Creative Construction Conference (2018)

Edited by: Miroslaw J. Skibniewski \& Miklos Hajdu

DOI 10.3311/CCC2018-017

Creative Construction Conference 2018, CCC 2018, 30 June - 3 July 2018, Ljubljana, Slovenia

\title{
A Study to Investigate Using Mobile Devices in the Construction Management Classroom as Rationalized by the Needs of Industry
}

\author{
Jeffrey Kim \\ Auburn University, 214 M. Miller Gorrie Center, Auburn, Alabama 36849, United States
}

\begin{abstract}
The construction management (CM) curriculum is constantly adjusting to keep pace with changes and developments in industry. Often times, CM programs will make use of an industry advisory committee to make sure that the program remains relevant and is aligned with the needs of industry. Technology is a common subject when faculty and industry professionals converge. At times the path is clear for what needs to be done, and other times no real direction is provided to make sure that universities are doing what is necessary to meet the needs of industry. In this study, a detailed survey was administered to industry professionals with the intent of using this data to inform CM academic programs in terms of what mobile device would be best to use. Eventually, this data will prove useful in helping faculty design course curricula to include the right kind of mobile device for the right type of learning activity.
\end{abstract}

(C) 2018 The Authors. Published by Diamond Congress Ltd., Budapest University of Technology and Economics Peer-review under responsibility of the scientific committee of the Creative Construction Conference 2018.

Keywords: mobile technology; active learning; construction education

\section{Introduction}

Preparing for new advancements in technology can be difficult, especially when there are many factors involved in evaluating them. An especially useful technology involves mobile devices that are so convenient that they have become an integral part of our personal lives. There are a myriad of devices available, each differing in size, capability, color, form-factor, price, manufacture and so on. These preferences make the task of evaluating and selecting a mobile device cumbersome. Additionally, these preferences can be deeply rooted in personal choices, further complicating a selection effort. Manufacturers have caught on to these challenges and have produced mobile devices that cater to the needs of virtually everyone. While this may be good for the consumer, it has been difficult for businesses that want to standardize their solutions to adapt. Businesses recognize that mobile devices can save time and provide much needed data to employees. However, businesses benefit most when the technology that they employ fits neatly into their information infrastructure. The constant design and feature churn in the new releases of mobile devices makes implementing them problematic. Unfortunately, businesses are not the only entities that struggle to implement mobile devices.

Academia is constantly creating learning experiences that mimic the experiences one has while in industry. This can be achieved through traditional class discussions, lectures and assessments, however, when technology is involved, the learning experience is enriched through a more active approach to teaching and [1]. Active learning engages students in such a way that they can begin to ask the "why" questions about their learning experiences [2]. It is important that academia teaches with the same types of equipment and resources that students will use in industry after 
they graduate. Therefore, it is not unreasonable to assume that academic institutions will struggle with similar mobile device decisions, much like their industry counterparts.

This research was conducted so that academic programs could prepare graduating students for a mobile working environment. Other benefits of this study illustrate how incorporating mobile devices in the construction management (CM) classroom increases active learning and student engagement. Lastly, mobile devices are the platform for other emerging innovative technologies, therefore, an academic program that incorporates course work that requires the use of mobile devices is preparing those students for the future construction industry workplace.

\section{Research Motivation and Past Research}

The construction management curriculum of today is focused on molding students to think creatively about ways to solve challenging problems. Changes within the industry, such as, the introduction of sustainability standards, increased safety protocols and the use of building information modeling (BIM) are creating an environment where creative thinking and resourceful problem solving reward businesses by setting them apart from their competitors [3]. Colleges and universities face a challenge in preparing students (and the future workforce) to be creative thinkers. The conventional classrooms are built around agrarian and industrial era models that are not well suited to teach students of the 21 st century $[4,5,6]$. In order to achieve a higher degree of learning and a deeper understanding, students need learning environments that foster active learning above traditional passive learning models and according to Cardullo [4], they will also need the right tools in the classroom to make this transition possible. As the renowned 20th century visionary and inventor, Richard Buckminster Fuller stated,

"If you want to teach people a new way of thinking, don't bother trying to teach them. Instead, give them a tool, the use of which will lead to new ways of thinking."

Research indicates that mobile technology allows for the "acquisition of knowledge regardless of location and time" [7]. The research further indicates that the proper use of mobile technology in the classroom can improve certain educational outcomes [1,8]. This fact coupled with the ubiquity [1] of mobile devices already in the hands of many students supports a motivation for using these devices in the classroom. Likewise, the academic community is aware of the success of mobile devices within the management of projects through numerous case studies and articles. Consequently, there is growing interest in mobile device research at academic institutions across the U.S., therefore, it is imperative to adopt an approach toward mobile device selection for academic institutions based on the same rigors that industry uses.

Mobile technology is seeing strong growth in the construction industry and this trend continues to rise [9,10,11]. For construction academics to remain relevant there must be a response to this interest in mobile technology. Demand for more mobile technologies in the classroom may be driven by the incoming student's themselves $[9,12,13,14]$. While this statement could arguably be applied to any curriculum at any learning institution it is important to note that it is particularly relevant to the needs of the construction industry and those that would prepare its future workforce. As early as 1993, Opfer acknowledged that the construction industry was a mobile environment. An environment where most of the participants were not confined to a single location, such as the case for the manufacturing industry. The environment of the construction site is dynamic and not static and mobile devices offers an opportunity to support these characteristics of the construction industry [15]. Therefore, connecting the need to educate students in classrooms more befitting of the 21 st century with the needs of the construction industry sets the direction for this research.

There have been many studies that investigate the benefits and challenges of active learning and the use of mobile technology in the classroom and many report the results of ways in which it should happen. A useful connectedness between student learning objectives and mobile devices would provide instructors with a blueprint for incorporating more mobile, active and student centered pedagogy in the CM classroom. This research will focus on exploring the various uses of mobile devices within the construction industry with the overall intent to inform the CM classroom on ways in which it can be used to better prepare graduating students. The following research questions will be addressed through this study:

- What purchase criteria are important when considering mobile devices?

- What are the current workforces' perceptions regarding mobile devices?

- How does the current workforce use mobile devices?

- What applications and features are most useful when using mobile devices? 


\section{Methodology}

In order to prepare students for the construction working environment, it is best to give them experiences at school that are similar to those that they will face when in industry. Likewise, the tools that they use should match the tools used in industry. Therefore, the focus for this research is on matching the preferred mobile device types that industry uses with those that should be used in the CM classroom. This research was designed to obtain feedback from industry concerning their experiences and perceptions about mobile devices. An electronic survey was distributed via email to construction industry advisors of the McWhorter School of Building Science at Auburn University. Additionally, the survey was made available through social media outlets of the Associated General Contractors Alabama Chapter and the Associated Builders and Contractors Georgia Chapter. 177 responses were received, however, in order to ensure relevance and consistency within the responses, 32 responses were rejected for the following reasons: 1.) the participant was not easily categorized as a member of an industry capable of providing relevant feedback for this study or 2.) the response to the survey was incomplete. This survey included both closed and open-ended questions designed to respond to the aforementioned research questions.

\section{Results}

\subsection{Demographics}

The participants in this survey were $86 \%$ male and $14 \%$ female and ranged in age from $44 \%$ classified as $B a b y$ Boomers (1941-1965), 37\% Generation X (1966-1980) and 19\% Generation $Y$ (1981-2000). Within the built environment, $24 \%$ identified as owners, $60 \%$ as builders (or trade crafts), $15 \%$ as designer/engineers and $6 \%$ as other. Participants reporting 1-5 years of work experience (6\%), 6-10 years (11\%), 11-20 years (22\%) and 20 years or more $(60 \%)$. Lastly, organizations ranged in size (in terms of annual revenue) Less than 1 million (4\%), 1 million to 10 million (15\%), 10 million to 25 million (18\%), 25 million to 100 million (20\%) and 100 million and above (43\%).

\subsection{Questions regarding mobile device selection criteria}

The purchase decision alone can be a daunting task for mobile devices when one considers all of the available options. When participants were asked to sort their preferred criteria for selecting a mobile device, they ordered their decisions in the following manner:

1. Most important - Quality

2. Important - Price

3. Somewhat Important - Manufacturer

4. Least Important - Word of Mouth

Quality, as the most important factor, is difficult to assess and may be a subjective variable, therefore, participants were asked about ruggedization of the device as a factor of quality that could be relatable to the construction industry. $61 \%$ of participants responded that they would prefer to have a ruggedized device and for those that indicated otherwise, a combined $88 \%$ of that group indicated that they would (Definitely yes to Probably yes) buy a ruggedized case to protect their mobile device.

Participants were asked to identify a price range that they considered average for the type and size of mobile device that they preferred:

- $6 \%$ - Less than $\$ 300$

- $14 \%-\$ 300-\$ 400$

- $21 \%$ - $\$ 400-\$ 500$

- $20 \%$ - $\$ 500$ - $\$ 600$

- $22 \%$ - $\$ 700-\$ 800$

- $7 \%$ - $\$ 800$ - $\$ 900$

- $10 \%$ - More than $\$ 900$ 
There is a wide selection of manufacturers to choose from for mobile device. Deciding on a mobile device based on the manufacturer is an important decision because by selecting a manufacturer you are devoting yourself to an operating system and a marketplace for available applications (apps) to run on the device. Participants ranked the preferred manufacturers in the following order:

1. Most Preferred - Apple

2. Preferred to Somewhat Preferred - Microsoft, Samsung and Google

3. Least Preferred - Blackberry

When asked about the ownership of the mobile device, $69 \%$ indicated that the company owned the device, $18 \%$ indicated that the employee owned the device but was compensated for its work-use and $7 \%$ used their own personal device without being compensated.

\subsection{Questions regarding the current workforces' perceptions regarding mobile devices}

Participants were asked about their habits and attitudes regarding the use of mobile devices, the details of which have been summarized in Figure 1. When asked how often they worked away from a fixed office location, $51 \%$ of the participants responded Often with only $2 \%$ responding Never. The participants were asked to rate the perceived effectiveness that mobile devices had on cost, time and quality of work. In terms of a cost benefit, a combined $96 \%$ indicated yes (Definitely Yes to Probably Yes) while the remaining 4\% indicated that there may not be a cost benefit. Considering if mobile devices save time, a combined $98 \%$ indicated yes (Definitely Yes to Probably Yes) while the remaining $2 \%$ indicated that there may not be a time savings benefit. Lastly, when asked if mobile devices benefited the quality of work, $43 \%$ indicated Definitely yes, $31 \%$ indicated Probably yes, $20 \%$ indicated it Might or might not, $4 \%$ indicated Probably not and 2\% indicated Definitely not.

How often do you work away from a fixed office space?

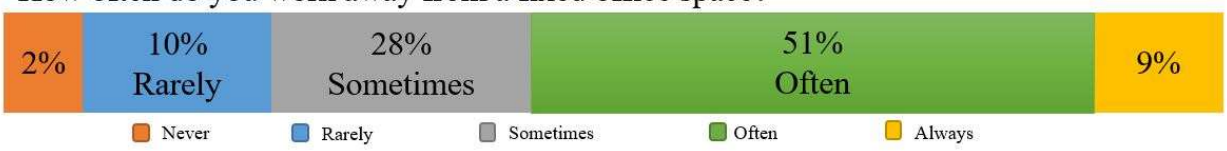

Is there a COST benefit to using mobile devices in the building industry?

\begin{tabular}{rc|c}
$67 \%$ & $29 \%$ & $3 \%$ \\
Definitely Yes & Probably Yes & $1 \%$ \\
\hline Definitely Yes $\quad \square$ Probably Yes & $\square$ Might or Might Not & $\square$ Probably Not $\quad \square$ Definitely Not
\end{tabular}

Is there a TIME benefit to using mobile devices in the building industry?

$\begin{array}{cccc}79 \% & 19 \% & 1 \% & 1 \% \\ & \text { Definitely Yes } & \text { Probably Yes } & 1 \%\end{array}$

Is there a QUALITY benefit to using mobile devices in the building industry?

\begin{tabular}{|c|c|c|c|c|}
\hline $\begin{array}{c}43 \% \\
\text { Definitely Yes }\end{array}$ & $\begin{array}{c}31 \% \\
\text { Probably Yes }\end{array}$ & $\begin{array}{c}20 \% \\
\text { Might or Might Not }\end{array}$ & $4 \%$ & $2 \%$ \\
\hline
\end{tabular}

Fig. 1. Habits and attitudes regarding the use of mobile devices.

Because so many participants indicated that they partly worked away from a fixed location, when further asked if they relied on a mobile (tablet sized) device when away from their fixed office location, 9\% responded Always, 32\% responded Often, 29\% responded Sometimes, 16\% responded Rarely and 14\% responded Never. Lastly, the participants were asked if a mobile device could replace their laptop or desktop computer and 4\% responded Always, $16 \%$ 
responded Most of the time, 37\% responded About half of the time, 39\% responded Sometimes and 5\% responded Never.

\subsection{Questions regarding the current workforces' use mobile devices}

Mobile devices are a part of many different processes within the construction industry. Participants were asked to rank these processes by considering how impactful mobile devices were to the success of that process. The following list represent those processes in order of most impactful to least impactful.

1. Project Management and Document Administration

2. Project Supervision and Work Coordination

3. Scheduling

4. BIM and VDC

5. Preconstruction and Cost Estimating

6. Accounting and Cost Management

7. Design and Engineering

8. Safety and Risk Management

9. Project Compliance

Participants were asked which age groups seemed to make the most use of mobile devices, $66 \%$ responded Employees aged 26 - 35 and 23\% responded Employees aged 20 - 25 while only 2\% responded Employees older than 45. Lastly, participants were asked to consider recently graduated students that have become junior level employees and rate their overall mobile device proficiencies. 31\% responded Extremely well, 33\% responded Very well, 29\% responded Moderately well, $5 \%$ responded Slightly well and 2\% responded Not well at all.

\subsection{Questions regarding mobile device applications and features}

It is important to note that the mobile device is a platform for running apps. These apps and native features are what create the usefulness of the mobile device. Participants were asked to provide some feedback on the features and apps that they found most useful in their mobile device. The open-ended responses were coded and categorized and are summarized in the table below (Table 2.).

Table 2. Preferred Features and App Categories

\begin{tabular}{|l|l|}
\hline CATEGORY & Frequency (\%) \\
\hline Email & $81(14 \%)$ \\
\hline Camera & $69(12 \%)$ \\
\hline Productivity App & $49(9 \%)$ \\
\hline PDF Management App & $47(8 \%)$ \\
\hline Project Management App & $44(8 \%)$ \\
\hline BIM App & $36(6 \%)$ \\
\hline Plan Management App & $33(6 \%)$ \\
\hline Map & $29(5 \%)$ \\
\hline Cloud Storage App & $28(5 \%)$ \\
\hline Web Browser & $24(4 \%)$ \\
\hline Text Messaging & $20(3 \%)$ \\
\hline Weather App & $20(3 \%)$ \\
\hline Calculator App & $15(3 \%)$ \\
\hline Video Communication App & $15(3 \%)$ \\
\hline Accounting App & $14(2 \%)$ \\
\hline
\end{tabular}




\begin{tabular}{|l|l|}
\hline Note Taking App & $14(2 \%)$ \\
\hline Calendar & $12(2 \%)$ \\
\hline Field Management App & $9(2 \%)$ \\
\hline Scheduling App & $8(1 \%)$ \\
\hline Safety App & $7(1 \%)$ \\
\hline
\end{tabular}

\section{Discussion}

\subsection{What purchase criteria are important when considering mobile devices?}

As previously stated, when purchasing mobile devices, there are several criteria to evaluate - often complicated through personal preference and bias. The data seem to indicate some personal bias may be present when the participants select "Quality" as the highest consideration. Quality is a subjective [16] decision and can be easily swayed by outside factors that are not easily comparable when making a purchase decision. However, the second most common consideration was "Price". A consideration that can easily be measured for a purchase decision. It is important to note that a low ranking received by the "Manufacturer" purchasing consideration was offset by the overwhelmingly high ranking for Apple products as the "Most Preferred" manufacturer. There are no conclusions about this distinction in this data and it should be explored further in future iterations of this research. "Price" was highly considered as a purchase decision and participants were almost evenly grouped in their preference about what price they would be willing to pay for the mobile device, $21 \%$ preferred $\$ 400-\$ 500,20 \%$ preferred $\$ 500-\$ 600$ and $22 \%$ preferred $\$ 700$ $\$ 800$. When considering the preferred price for a mobile device, the data indicate that the range is somewhere between $\$ 400$ and $\$ 800$. In terms of the size of organizations that are making these purchase decisions, it could be assumed that with a price point between $\$ 400$ and $\$ 800$, these mobile devices are regarded more as consumable equipment rather than durable, long lasting equipment.

Lastly, the participants were asked if they owned the mobile device or if their company owned the device. The majority of participants indicated that the company owns the device. As the use of mobile devices becomes more commonplace, the need for businesses to offer them as a way of keeping their employees mobile and able to access the most up-to-date data will increase. This presents security problems for businesses as their data is now spread thinner across more devices. Additionally, businesses prefer to operate with some standards and by controlling the devices (through ownership) they can also control the types of devices that are used to access their data. Similarly, universities will be concerned about security breaches and standardization of devices. Therefore, it is advisable to align a purchase decision about mobile devices, in the same manner as industry.

\subsection{What are the current workforces' perceptions regarding mobile devices?}

This research question is important because it gauges how the workforce perceives the importance of mobility and if it practices it. Understanding this perception can help academia structure more curricula that is aligned with the business practices of industry. $51 \%$ of the participants indicated that they "often" work away from a "fixed" office space (Figure 1.). Most (a combined 41\%) also indicated in a follow up question that they use a mobile device when they are away from their office. There is consistency with these results and those found in another industry wide survey conducted by JB Knowledge [11] that reveals an increasing trend in the use of mobile devices within industry. These results support industry's increasing reliance on mobile devices and should not be overlooked by academia when considering incorporating mobile devices in the CM classroom curricula.

Participants of this study were asked to provide their perceptions regarding cost, time and quality when using a mobile device. There were significant cost and time benefits as perceived by the participants, however, in terms of quality, the results were muted (Figure 1.). Participants also responded to the interchangeability of mobile devices with their laptop and/or desktop computing devices. These results were also muted in that the majority of participants only Half of the time (37\%) or Sometimes (39\%) used a mobile device as a replacement to their laptop and/or desktop. The only distinction that can be presumed here is that there are still some work tasks that the participants were unable to clearly attribute to quality through the use of a mobile device and some work tasks are still only achievable with legacy computing devices. 


\subsection{How does the current workforce use mobile devices?}

The participants were asked to identify the age group of employees that seemed to make most use of mobile devices in their company. A significant number $(66 \%)$ indicated a group of employees that had been with the company at least five years (age group 26-35) were more adept at using mobile devices. This indicates that there is a period of time in which employees develop a mobile proficiency in their work tasks. Perhaps a period of time is necessary to gain experience before the employee is considered effective as a mobile device user. Notwithstanding, the participants did indicated that the graduating students are exhibiting mobile device proficiencies (a combined $64 \%$ responded Extremely well to Very well).

\subsection{What applications and features are most useful when using mobile devices?}

Mobile devices are built to bring utility in a way that is convenient to the end user. They achieve this utility through the various features that are built into the devices and through the many apps that can be added to them later. Because this is an important part of mobile devices, this survey asked the participants through open-ended feedback to define as many features and apps they found useful when using their mobile device. 574 features and apps were recorded by the participants. The responses were coded and categorized to reveal the most frequently used features and apps (Table 2.). It is not surprising that "Email" and "Camera" use topped the list with $14 \%$ and $12 \%$ respectively. Productivity apps such as a word processor or spreadsheet application were third in the list. A continued review of the list in Table 2., and it becomes apparent that the most frequent uses for the mobile device are similar in nature to those applications found on a laptop or desktop computer. This makes a strong case for the replacement of those legacy computing devices over time and an indication that training at academic institutions with the use of mobile devices is essential.

\section{Conclusion}

This study has focused particular attention on the perceptions of industry and how they are making use of mobile devices. It should be noted that the cross section of the industry analyzed was very narrow, in fact, it is characteristically industry members from the Southeastern United States. However, in terms of the scope of this research, there is ample data to start the development of a curriculum that includes elements of mobile technology in order to improve the skill set of graduating students. It is advisable to increase the research population to overcome regional attitudes toward technology use within the industry. For instance, in a McGraw-Hill SmartMarket Report on BIM technology, the West and Midwest regions of the United States have an adoption rate of $77 \%$ and $73 \%$ respectively compared to the South which had a $68 \%$ adoption rate [17]. A similar attitude toward mobile technology use could exist and needs to be validated with further research.

The objective of this research in preparing the graduating student for the future workforce would not be complete if the needs of industry were ignored, therefore, an understanding of how industry uses mobile devices was an additional motivation for this study. The study provided some insight through the various uses that participants shared through an open-ended response. As these responses were coded, it became apparent that they could be mapped to student learning objectives tied to course learning objectives and thereby become an integral part of an academic program. This list of feature and apps (Table 2.) should be researched further in order to initiate the implementation of mobility in the CM classroom.

Overall, the demographics of this study included some members from industry that have a significant amount of experience and it is apparent from their responses that they value what mobile devices can bring to the industry in terms of productivity. Consequently, in much the same way that building information modeling dispersed throughout the industry, so too can the use of mobile devices. While we are seeing this now, as evidenced by the survey responses, there seems to be a lack of some truly innovative uses for mobile devices. There was no mention of mixed reality, coordination with drones was only scarcely mentioned and BIM was 6th on the list of most used features and apps. It will require the next generation's conviction to innovate - but they cannot begin that process if they are not exposed to it at some level while they are still in school. This point is best illustrated by John Dewey in Democracy and Education, where he predicted that "if we teach today's students as we taught yesterday's we rob them of tomorrow" [18]. 


\section{References}

[1] Chen, B., Seilhamer, R., Bennett, L., \& Bauer, S. (2015). "Students' mobile learning practices in higher education: A multi-year study." Educause Review.

[2] Bonwell, C. C., \& Eison, J. A. (1991). “Active Learning: Creating Excitement in the Classroom.” (D. Office of Educational Research and Improvement (ED), Washington, Ed.), ASHE-ERIC Higher Education Report. ERIC Publications. Retrieved March 26, 2018 (http://files.eric.ed.gov/fulltext/ED336049.pdf).

[3] Hillebrandt, P. M. (1985). "Economic theory and the construction industry." Springer. P. 25.

[4] Cardullo, V. M., Wilson, N. S., \& Zygouris-Coe, V. (2015). "Enhanced student engagement through active learning and emerging technologies." Handbook of Research on Educational Technology Integration and Active Learning, pp. 1-18.

[5] Maeda, Y., Yoon, S. Y., \& Lafayette, W. (2011). "Measuring Spatial Ability of First - Year Engineering Students With the Revised PSVT: R." American Society for Engineering Education, p. 19.

[6] Peterson, P. E. (2010). "Saving schools: From Horace Mann to virtual learning." Harvard University Press. Retrieved March 26, 2018 (https://books.google.com/books?hl=en\&lr=\&id=XOFUesyAmFoC\&oi=fnd\&pg=PR9\&dq=saving + schools: + paul + peterson\&ots=Xhc1DVD t2r\&sig=gHvkDxwwqjNE9i8ABgSM2Q1qBwU\#v=onepage\&q=saving schools\%3A paul peterson\&f=false).

[7] Motiwalla, L. F. (2007). "Mobile learning: A framework and evaluation." Computers \& Education, 49(3), pp. 581-596. Retrieved March 26, 2018 (http://ac.els-cdn.com/S0360131505001569/1-s2.0-S0360131505001569-main.pdf?_tid=903e0b98-fdd9-11e6-8e5600000aab0f01\&acdnat=1488302335_284bflba55b5d51bf44a5416101e4eb8).

[8] Cline, R. C., \& Davis, K. A. (2015). "ŪS Construction Management Students Comfort Level With and Knowledge of Mobile Technologies." 122nd ASEE Annual Conference \& Exposition, (26) p. 1.

[9] Dahlstrom, E., Walker, J. D., \& Dziuban, C. (2014). "ECAR study of undergraduate students and information technology.” Educause Center for Analysis and Research. Retrieved March 26, 2018 (https://library.educause.edu/ /media/files/library/2014/10/ers1406.pdf). pp. 5, 9, 17 \& 20.

[10] Evans, M. A., \& Johri, A. (2008). "Facilitating guided participation through mobile technologies: designing creative learning environments for self and others." Journal of Computing in Higher Education, 20(2), pp. 92-105. Retrieved March 26, 2018 (https://link.springer.com/article/10.1007/s12528-008-9004-1/fulltext.html).

[11] JB Knowledge. (2017). The 6th Annual Construction TEchnology Report.

[12] Harris Poll. (2014). "Pearson Student Mobile Device Survey 2014: National Report: Students in Grades 4-12.” Retrieved March 26, 2018 (http://www.pearsoned.com/wp-content/uploads/Pearson-K12-Student-Mobile-Device-Survey-050914-PUBLIC-Report.pdf).

[13] Harris Poll. (2015). "Pearson Student Mobile Device Survey 2015".

[14] The News Media Consortium. (2013). "Technology Outlook for STEM + Education 2013-2018".

[15] Opfer, N. D. (1993). "Mobile Computing in the Construction Industry." ASC Proceedings of the 29th Annual Conference, p. 145.

[16] Ghose, A., \& Ipeirotis, P. G. (2006). "Designing Ranking Systems for Consumer Reviews: The Impact of Review Subjectivity on Product Sales and Review Quality." Proceedings of the International Converence on Decision Support Systems, (March), pp. 1-25. Retrieved March 26, 2018 (https://doi.org/10.1145/1282100.1282158).

[17] McGraw Hill Construction. (2012). "The Business Value of BIM in North America." SmartMarket Report.

[18] Dewey, J. (1903). "Democracy in education.” The Elementary School Teacher, 4(4), pp. 193-204. 